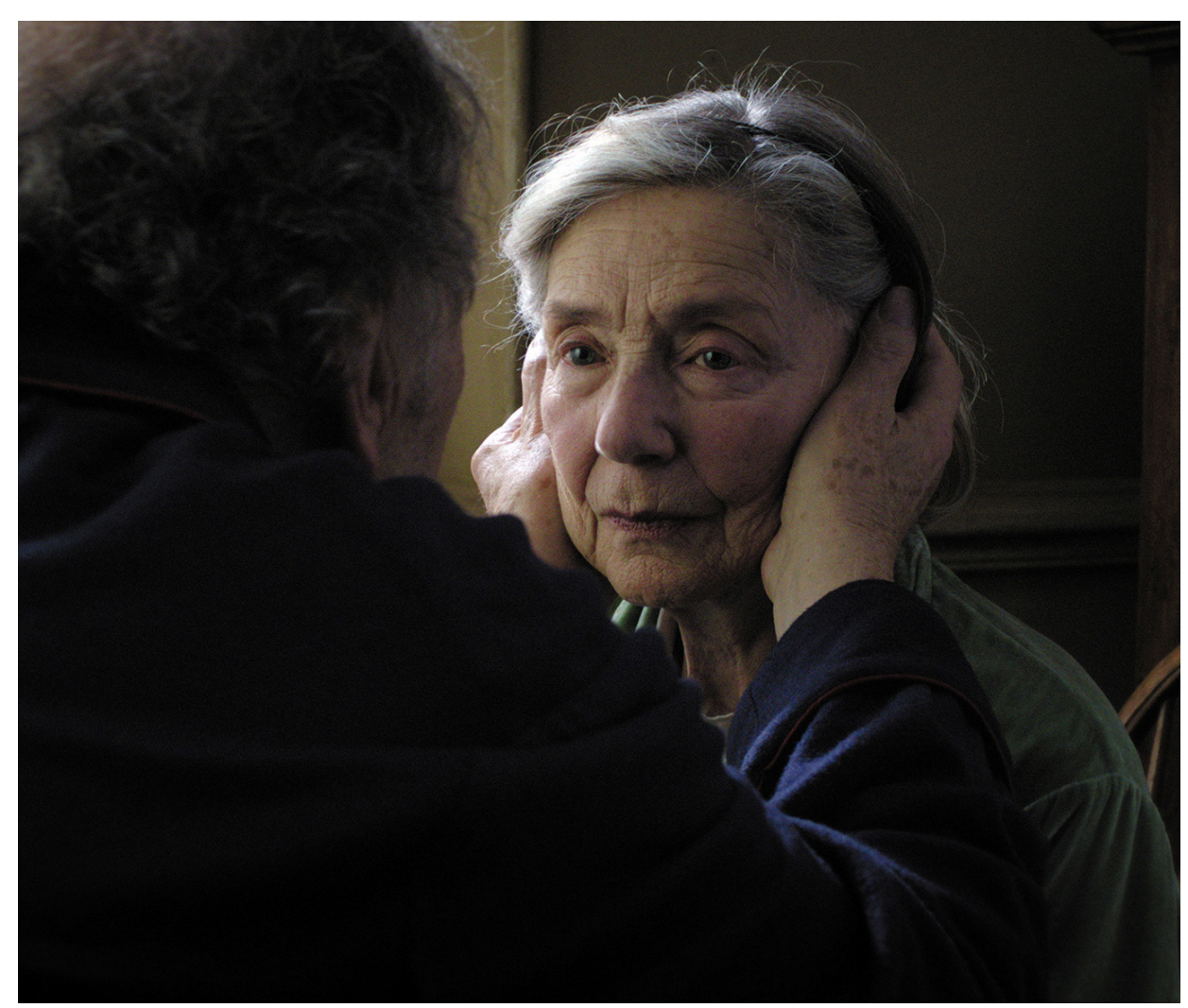

\title{
EL OTRO EN EL ESPEJO: “AMOUR” DE MICHAEL HANEKE
}

\author{
THE OTHER IN THE MIRROR: \\ "AMOUR" BY MICHAEL HANEKE
}

Sergio García Guillem / s.gguillem91@hotmail.es

UNIVERSITÉ PARIS 8 


\section{RESUMEN}

El último largometraje de Michael Haneke, Amour (2012), nos brinda una poética lúcida y desesperada de esa última estación humana que supone la vejez y la descomposición corpórea, pero también un bello y triste relato sobre ese fenómeno tan paradoxal que resulta el amor entre dos individuos. A través de un minucioso análisis del aparato cinematográfico, junto a la crítica psicoanalítica -en este caso a través del binomio Heimlich/Unheimlich freudiano-, intentaremos ofrecer una posible y nueva interpretación del film hanekiano.

PALABRAS CLAVE

Amour, Michael Haneke, muerte, enfermedad, lucidez, Heimlich/Unheimlich, psicoanálisis.

\section{ABSTRACT}

The last film of Michael Haneke's, Amour (2012), offers us a lucid and despaired poetics of this last human station that implies the oldness and the corporeal decomposition, but also a beautiful and sad narrative on this paradoxical phenomenon that is the love between two human beings. Through the critical device of a cinematographic device, together with the psychoanalytic critique, in this case through the Freudian binomial Heimlich/Unheimlich, we will try to display a possible interpretation of the hanekian film.

KEYWORDS

Amour, Michael Haneke, death, illness, lucidity, Heimlich/Unheimlich, psychoanalysis.

Recibido: 13 de mayo de 2014

Aceptado: 17 de noviembre de 2014 
"Dice que no sabe del miedo de la muerte al amor dice que tiene miedo de la muerte del amor dice que el amor es muerte de miedo dice que la muerte es miedo es amor dice que no sabe..." Alejandra Pizarnik, "Poesía completa"

\section{INTRODUCCIÓN}

En una entrevista ofrecida por la prensa alemana Die Zeit en 2006, Michael Haneke afirmó: “[...] la verdadera belleza es invisible a los ojos". El poliédrico cine del director austriaco rinde de esta forma muchas cuentas con una estética -poética al fin y al cabo- del silencio y lo invisible. La potencia de sus imágenes visuales, desde Der siebente Kontinen (El séptimo continente, 1989) y Funny Games (1997), pasando por La Pianiste ( $L a$ Pianista, 2001), Caché (Escondido, 2005) o Das weiße Band (La cinta blanca, 2009), hasta llegar al galardonado film que nos convoca, Amour (Amor, 2012), abren profundas brechas en las raíces de lo cotidiano. Elementos tan finitos y naturales como la vida, la muerte, la violencia psicosomática, la senectud o la soledad brotan de su poesía fílmica. Con grandes pinceladas de la tradición (Godard, Pasolini, Bergman, Fellini o Antonioni), Haneke se erige como uno de los baluartes actuales de la cinematografía en el siglo XXI. Al igual que en la línea de sus influencias cinematográficas, el director austriaco posee una profunda y crítica visión de la condición contemporánea, de la angustia y el tedio que el ser humano desarrolla ante el transcurso de sus infinitas circunstancias, empleando la terminología orteguiana. Uno de sus referentes cinematográficos más destacados es, como acabamos de comentar, el director italiano, Michelangelo Antonioni, del cual parece adaptar los tiempos muertos y determinados recortes de la imagen, lo que debería proyectarse o lo que no, incidiendo de esta forma en cierta cartografía pictórica en la composición de sus imágenes; acompaña también la influencia en esos primeros planos, tanto de los rostros de los personajes como del espacio que los rodea. En ambos directores, es el mundo burgués el que nutre en su gran mayoría el contenido de las secuencias.

La misión de Haneke resulta, a través tanto de su propio estilo como de sus numerosas influencias, y en un compás muy kafkiano, la de llevar todo aquello que resulte aislado y moral a cierto sinónimo de vida (in)finita, transformando el azar en algo conforme a la ley, señalando a pesar de ello la preeminencia de cierta caracterización del espíritu entre las onduladas tensiones de una energía moral e intelectual. Como comenta Catherine Wheatley en su estudio sobre el director, "Haneke's films are thus a continuation of an ongoing tradition of social criticism and popular art that has a specifically Austrian slant to it [...] Haneke wants his films to be reflexive, to theorise themselves. But he also wants them to break with the dominant cine-televisual forms" ${ }^{\text {. El cine }}$ del director austriaco se enfrenta a las convenciones del llamado "cine de masas", en muchas ocasiones relacionado con determinada producción hollywoodiense. Parece así embarcarse en un proyecto cinematográfico que desea de(s) construir esa alienación, término empleado por Haneke y por el propio Antonioni, del cine hegemónico. Ofrece así, en unos primeros planos, la llave a sus espectadores para, a la postre, lanzarla al más profundo de los abismos de la conciencia y la subjetividad. La poética hanekiana brinda al espectador el (dis)placer de ser su propio crítico, "an spectator willingly passive, asking them instead to be active [...] and to take responsability for their part in the workings of the cinematic institution"?.

El cine de Michael Haneke introduce así cierto coraje de tipo psicológico en el espectador

\footnotetext{
1 "Los films de Haneke son todos ellos una continuación del tradicional desarrollo del criticismo social y del arte popular que tiene trazos austriacos muy específicos [...] Haneke quiere de sus films ejercicios reflexivos, para teorizar sobre ellos mismos" (Cf. WHEATLEY, Catherine (2009): Michael Haneke's Cinema. The Ethic of the Image, Berghahn Books, USA, pp. 20, 24. La traducción es nuestra).

2 "[...]como espectador voluntariamente pasivo, pero al mismo tiempo cuestionándose sobre su posición activa [...] tomando responsabilidad en su parte dentro de la institución cinematográfica" (Idem, p. 36).
} 
que se ve representado en todos y cada uno de los versos de su poética filmica. La composición poético-cinematográfica repasa nuestras propias motivaciones, aspiraciones y miedos, al igual que las premisas e imperativos más ahondados en nuestras virtudes y vicios éticos. Nosotros, los espectadores, nos unimos a esta lúcida poética que nos hace reflexionar desde el horror vacui que la habita, somos potencialmente activos ante los recursos que el director nos deja en cada imagen, en cada gesto, palabra o nota musical. Delimitando las fronteras de nuestra exposición, y como posteriormente comprobaremos con el análisis de su más reciente largometraje, Amour (2012), todas estas características que asignamos a su cinematografía, y a sus más reconocidas influencias cinematográficas se introducirán en lo más profundo de nuestras entrañas, arrojándonos fríamente y sin compasión ante la cruda mirada de lo humano.

De este modo, el propósito de nuestro análisis se iniciará a través de una revisión de corte filosófico de los leitmotiv que rondan el film hanekiano, a saber, una serie de reflexiones acerca de la ambivalencia del "otro", del fenómeno de la muerte, la soledad o la angustia, y ante todo, una plural introspección hacia esa fenomenología del amor que se encuentra dentro del film. Posteriormente, y guardando la misma línea de análisis, se procederá a interrelacionar el fenómeno de la muerte y la degradación corporal con ese "otro" en el espejo que refleja, en un mismo compás, lo desconocido junto con el sentimiento de lo más familiar y característico del ser humano; punto limítrofe con las reflexiones psicoanalíticas, de corte freudiano, en torno a las múltiples representaciones de "lo siniestro" (Unheimlich/Heimlich). Y así, más que sólo un esquema de narración exclusivamente de corte moralista, nos encontramos con un Haneke que no resulta para nada la figura de un director-pedagogo, como muchos gustan de colocarlo entre sus filas -y como el mismo director rechaza en muchas de sus entrevistas-, sino que su cine acaba mutando en una constante vía de fuga ante la convencionalidad. Haneke, en el magisterio de sus producciones, deviene una plural forma del director-artista, que sigue en cierta línea al claroscuro de la figura del "filósofo-artista". Con la ayuda del escalpelo filosófico-psicoanalítico, y aunando ciertas anotaciones sobre una concreta estética cinematográfica, intentaremos diseccionar el film que nos convoca en esta ocasión.

\section{LA ÚLTIMA BAGATELA: "AMOUR" (2012)}

La ágil melodía de una Bagatela abre el telón del último film de Michael Haneke, donde ante un magistral teatro repleto de una aparente masa anónima, el ritmo de la cámara comienza a marcar su compás a través de la música. El desolador viaje que suele acompañar a los films de Haneke es un claro ataque a la conciencia del espectador. Resulta imposible mantener una posición pasiva frente a la consecutiva serie de escenas, sino que son los propios espectadores los que crean parte del universo personal y crítico de sus producciones. La violencia que precede a sus anteriores films encuentra en Amour la expresión de su fineza psicológica más desgarradora. Este film es, a fin de cuentas, la batalla campal de todo ser humano; aquella a la que todos debemos hacer frente: la vejez, la decrepitud de un cuerpo que se encuentra con la enfermedad, es decir, con la autoconciencia de su propia finitud, la soledad del moribundo que no encuentra refugio sino en sí mismo y en la persona amada, acompañando a ésta en una funesta melodía de muerte donde descansan las inagotables notas del piano. Amour nos obliga de igual forma a repensar cierta "meta-cinematografia”, replanteando ciertos presupuestos partiendo de una determinada estética cinematográfica y de una comprensión del cine que, como el propio Haneke reitera, colisiona con la tradición clásica de la empresa hollywoodiense y se atreve a releer -también a repensar-, los frutos más prolijos de la tradición cinematográfica.

Anne (Emmanuelle Riva) y Georges (JeanLouis Trintignant) se nos presentan como una pareja octogenaria, apasionados y entendidos en música, posteriormente a través de la narración filmica conoceremos que ambos eran profesio- 
nales en dicha arte, que remontan día tras día los vacíos que puede dejar una jubilación; rellenando ese largo tiempo libre de gustos y aficiones compartidos durante toda una vida. Ya desde las primeras escenas, el flujo hanekiano que se preserva en la mirada, el gesto, una pura fenomenología del tacto y la sensación, junto con los escasos diálogos, queda especialmente patente en la anciana pareja.
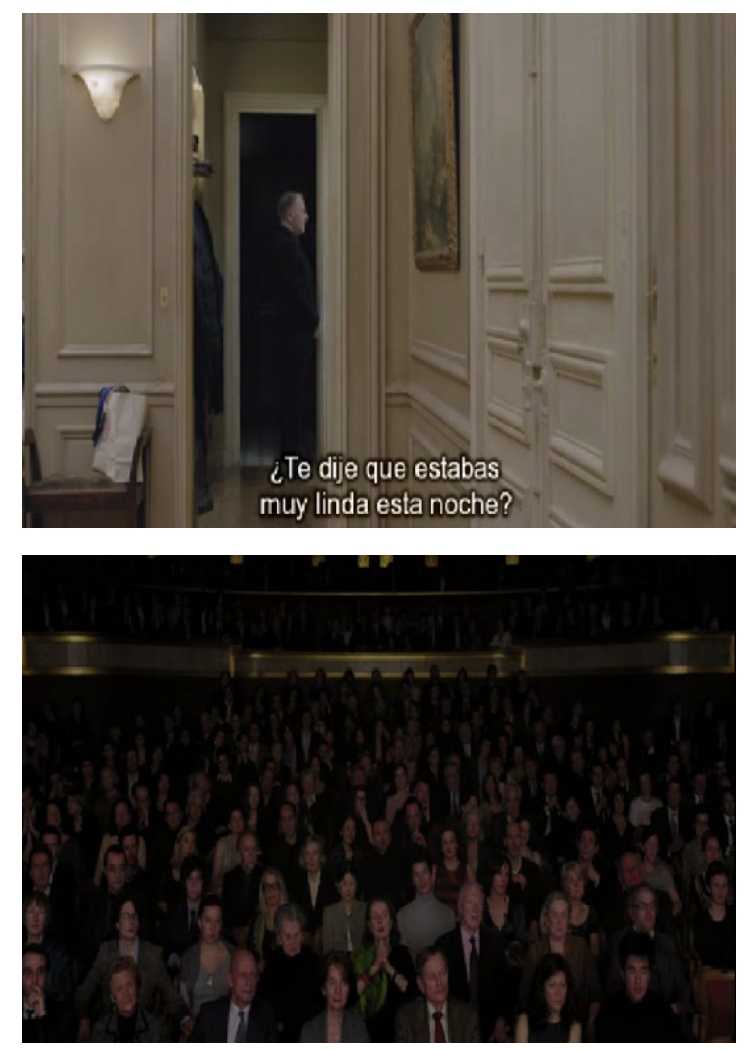

Todos los efectos de lo cotidiano se presentan entre las paredes del apartamento parisino, espacio extremadamente importante a lo largo del film. Parece haber incluso hasta una rutina: Anne preparándole el desayuno a Georges mientras éste conversa banalmente por teléfono, hasta que llega el punto crucial, primer abismo en el relato, donde se fisuran todas las figuras de lo cotidiano. Durante un corto periodo de tiempo, Anne queda absorta en sí misma, petrificada ante la mirada atenta de Georges, no reacciona, mantiene su compasiva mirada fija en los ojos de su compañero.

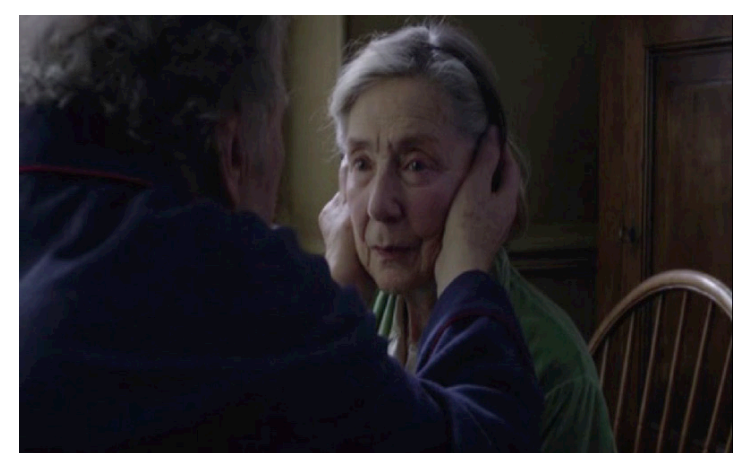

Es en este pequeño suspiro de la narración donde comienza el fenómeno de la degradación, Anne queda paralizada de un lado de su cuerpo al obstruírsele la carótida, interrumpiendo así su cotidiana vida y aflorando de esta forma la conciencia de una finitud anunciada. Las siguientes escenas marcan un punto y seguido en la narración. Escena tras escena, el apartamento se encuentra vacío - un eterno retorno de escenas desde el inicio hasta el apogeo final del film-, totalmente desolado, comienza a respirar los vapores de sentimientos encontrados. Es este escenario, el apartamento donde mora la conjugación de su amor, un personaje más del film hanekiano. La escena siguiente pone inmediatamente en juego el rol de la hija de Anne y Georges, Eva (Isabelle Huppert). La hija de la pareja, visitante esporádica debido a su trabajo en el extranjero y a su desgraciada relación amorosa, reencarna el espíritu de la opinión social común; tanto ella como su británico marido Geoff (William Shimell) representan el brote de esperanza ante ciertos aspectos propios de la biomedicina y el conocimiento de la técnica humana, poniendo siempre en tela de juicio la (in)capacidad de Georges para tratar y cuidar a Anne. La joven pareja insinúa en numerosas ocasiones el futuro internamiento de su madre en una residencia de ancianos. Eva, después de esa primera y fría discusión con su padre donde apenas llegan a tocarse, conversa con su padre y recupera, a través de un fortuito y compasivo comentario, el valor de la carnalidad, del cuerpo enamorado. La hija de los protagonistas se encarga de esta forma de rememorar aquel pasado que, a pesar de traer emotivos 
recuerdos de toda una vida, hiere profundamente ante el fruto de lo inminente.
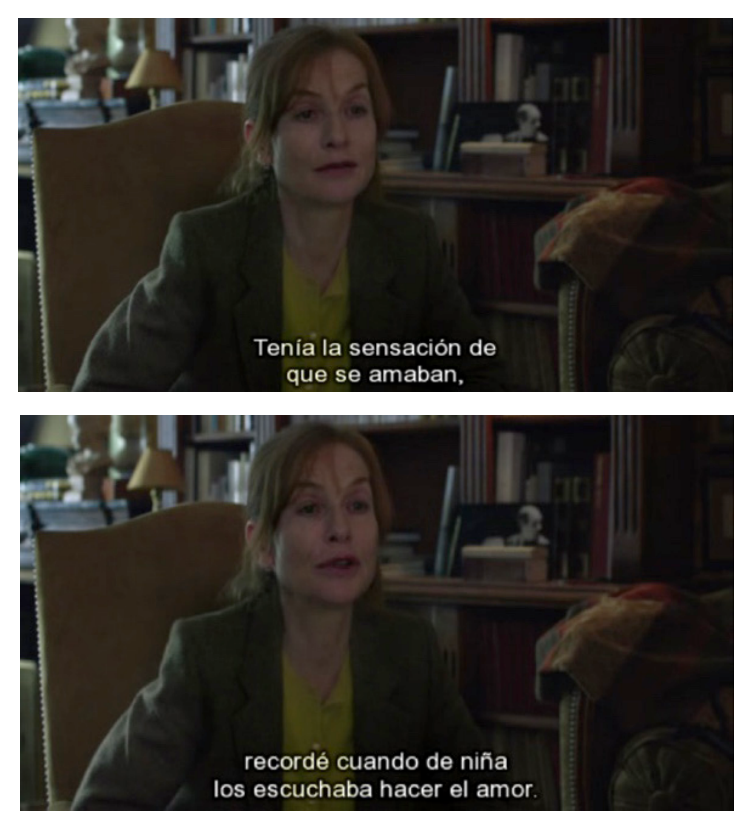

Comienza a partir de esta serie de escenas un poema del extrañamiento hecho imagen; la enfermedad, la degradación del cuerpo, es observada por Anne como un ser extranjero que se aposenta en ella pero que, al mismo tiempo, es uno de los compañeros más familiares en el camino de la finitud. Anne, contradiciendo el discurso tanto de su hija como de su yerno, hace prometer a Georges el no llevarla nunca más al hospital ("Georges, ne me ramènes plus jamais à l'hôpital»³), sea cual sea su estado de gravedad. Esta cotidianidad truncada continua su ritmo pero, así como en los primeros planos la tranquilidad y el sosiego recorrían el espíritu de ambos personajes, a partir de la presencia de la enfermedad todo se vuelve inhóspito y tenso, la muerte ha iniciado su camino para apoderarse del octogenario cuerpo de la protagonista. Muy a pesar de ello, Anne, lúcida en cuanto a su condición y asumiendo el trayecto hacia su más próxima estación, intenta siempre que Georges se ocupe de su propio universo cotidiano. Las esce-

3 "Georges, no me vuelvas a llevar jamás al hospital" (La traducción es nuestra). nas parecen eternizarse a cada segundo, vemos como día tras día Georges ayuda continuamente a su esposa ante dificultades tales como tomar un baño, ir al servicio, el propio acto de comer o simplemente la formulación continua de ciertos relatos externos que alivien en cierta manera la pesadumbre de su condición. Tanto el silencio, como en ocasiones el humor y la ternura, inundan las escenas, y es aquí donde la fenomenología de la caricia y el gesto, que con gran plasticidad insinúa Haneke, toma parte del potencial poético de cada escena.
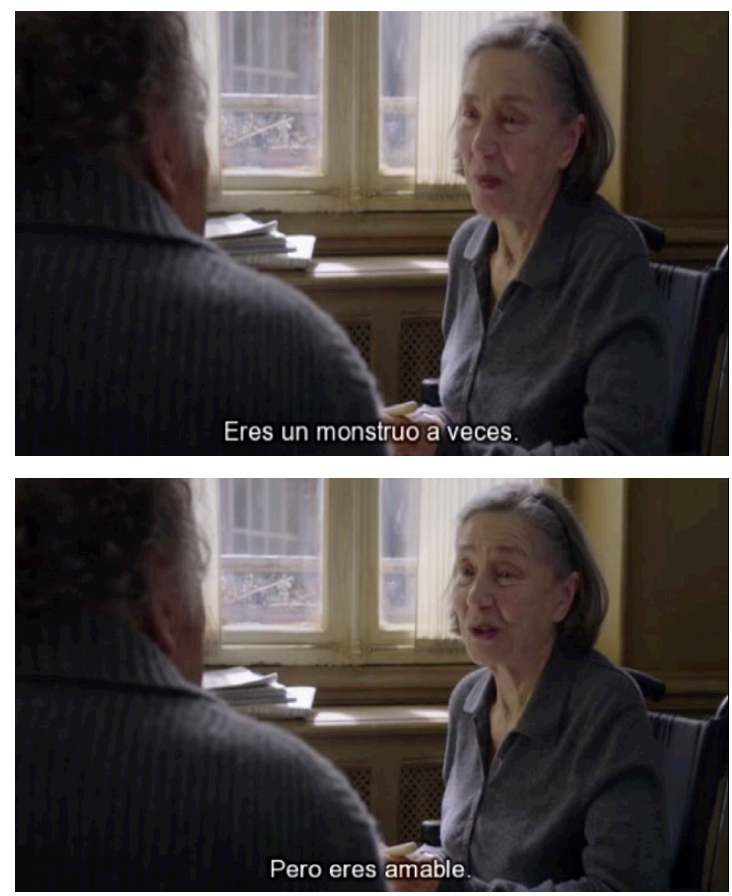

Después de que en momentos posteriores, la pareja comente la defunción de uno de sus amigos entre bromas y suspiros, Georges acude al entierro (ese otro teatro de la vida), pero a su vuelta se encuentra a Anne inerte bajo la ventana y la frondosa lluvia. Durante un silencio casi terrorífico la ayuda a ponerse en pie y sentarse en la butaca del salón. Es en este espacio donde Anne exige a Georges que le cuente de forma detallada cómo ha transcurrido el funeral. La reacción de Georges es narrar el esperpéntico funeral que ha presenciado, y donde la respuesta de Anne será la siguiente: "Il n'y a pas aucune raison 
pour continuer à vivre [...] Je sais que ça ne peut qu'empirer..."'.
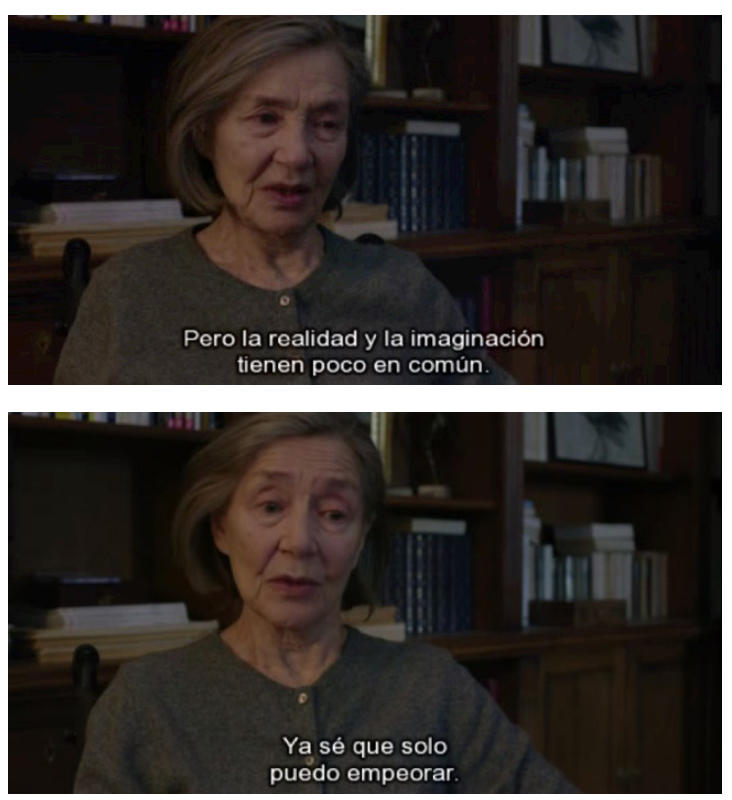

El ocaso al que abocan los frutos de la enfermedad, la decrepitud y la vejez, sobre todo ante la proximidad de una muerte inminente, hacen perder todo atisbo de esperanza en Anne, y por ende en Georges. Como comentábamos, la lucidez de Anne en cuanto a su condición es claramente digna de atención. Es esta mencionada escena una de las más oscuras de todo el largometraje. Anne se encuentra cara a cara con el extrañamiento de su condición, le faltan fuerzas para continuar luchando, porque ya ha vivido plenamente su vida. Muy a pesar de que la enfermedad de Anne y su involución ocupen gran parte de la perspectiva en el film, convirtiéndose quizá en el personaje femenino psicológicamente más elaborado de la poética cinematográfica de Haneke, la figura de Georges abarca un fenómeno de altibajos muy estridentes, desde el proceso de aceptación, e incluso de posible normalización ante la vuelta a lo cotidiano, hasta esta muestra de impotencia vital en la que entra Anne y que hace residir a Georges en una espiral de

4 "No hay ninguna razón para continuar viviendo [existiendo] Sé que esto no puede más que empeorar..." (La traducción es nuestra). silenciosa desesperación. Como bien justifica el título de su film, no partimos de una preconcebida cartografía del amor, sino que el amor en el film, dentro de su vertiente fenomenológica, fluye a través de las miradas, los gestos, las escasas palabras, las promesas, constituyendo un hálito de vida en un apartamento y un espíritu dominados por el trágico sentimiento de la muerte y la enfermedad. Es de este modo como una posible reflexión sobre el fenómeno del amor en este film no puede ser albergada en un simple párrafo donde se oriente al lector en dónde o cómo puede identificar esas señales entre la anciana pareja. El amor, en el caso de Anne y Georges, se inmortaliza tanto en la más cálida carcajada como en la más gélida de las miradas. El momento en el que Alexander, el joven aprendiz y pianista, alumno de ambos protagonistas, aparece de casualidad ofrece, de igual forma, un punto común donde el amor de Anne y Georges se eterniza, se acaricia, se susurra entre las teclas de un piano compartido en la historia de dos vidas.

La música, que en esta ocasión es rememorada por Alexander a petición de Anne, invoca el camino ya recorrido, todo posible sentimiento, tanto positivo como negativo, queda así impregnado de esta fúnebre melodía. La clave musical marca de esta manera el proceso de elipsis que el propio Haneke considera como pieza fundamental de todo misterio dentro del arte cinematográfico. La nota escrita por Alexander, que acompaña a la grabación de su nuevo disco, mantiene otro de los leitmotiv del film: "Ha sido una bella y triste velada en vuestro hogar". La música, como opinaba Cioran, es lo único que puede inmortalizarnos, es sinónimo de este amor impersonal, casi escéptico, aquél que nos acerca a una trascendencia más allá de todo lo cotidiano, donde el significado que tanto le falta a Anne a través de su condición cobra paulatinamente cierto grado de sentido ${ }^{5}$.

5 "Poseemos en nosotros mismos toda la música: yace en las capas más profundas del recuerdo. Todo lo que es musical es una cuestión de reminiscencia" (Cf. CIORAN, Emil (2001): De lágrimas y de santos, traducción de Rafael Panizo, Tusquets editorial, Barcelona, p. 35). 

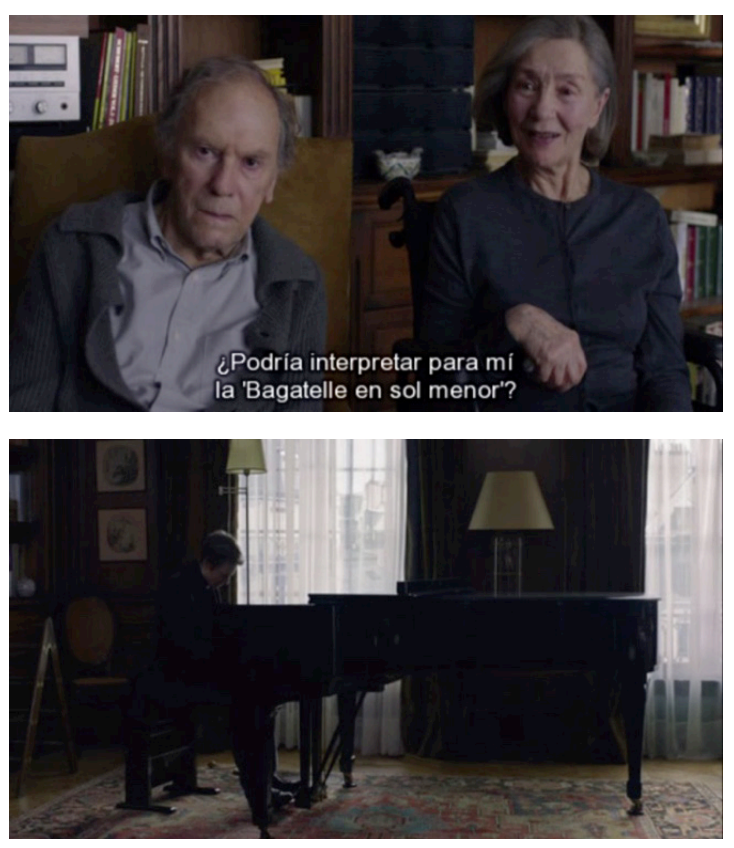

Anne escucha igualmente cómo Georges libera su frustración y sus preocupaciones a través de la música; hay así una imposibilidad de seguir adelante ante el desvanecimiento de lo finito, al igual que en el momento en el que reciben el disco y la nota de Alexander. A los pocos segundos de haber comenzado a escucharlo, ante la inmanencia de la destrucción corpórea, Anne exige categóricamente a Georges que detenga la música con una expresión amarga e inmisericorde. Todo ello se muestra a través de pequeños fragmentos poéticos, una cruda poesía de la vida, pero no del valor inerte y presente del hecho de vivir, sino el sentimiento de una existencia en continuo movimiento con principio, interludio y final, como aquella bagatela que eterniza desde un principio el film.

Las siguientes escenas tienen una especial relevancia en el orden de cierto escenario psíquico de los personajes. La escena comienza con el cepillado de dientes nocturno de Georges, hasta que suena el timbre de la puerta. Georges abre y contempla que nadie se encuentra al otro lado del espacio de la casa. Ante él se ofrece una imagen extraña, la puerta del ascensor aparece cerrada con maderos clavados en el exterior. En ese mismo instante se escucha la temerosa voz de Anne preguntando quién está al otro lado de la puerta. Georges continua preguntando en vano, nadie responde a su pregunta. El anciano se dirige hacia el pasillo y al girar, ante su profundo asombro, se encuentra con que la prolongación del pasillo está totalmente inundada; en cuestión de segundos, una mano surge de detrás de su figura tapando a Georges la boca, justo después éste se despierta exaltado y con un profundo grito de tan siniestra pesadilla.
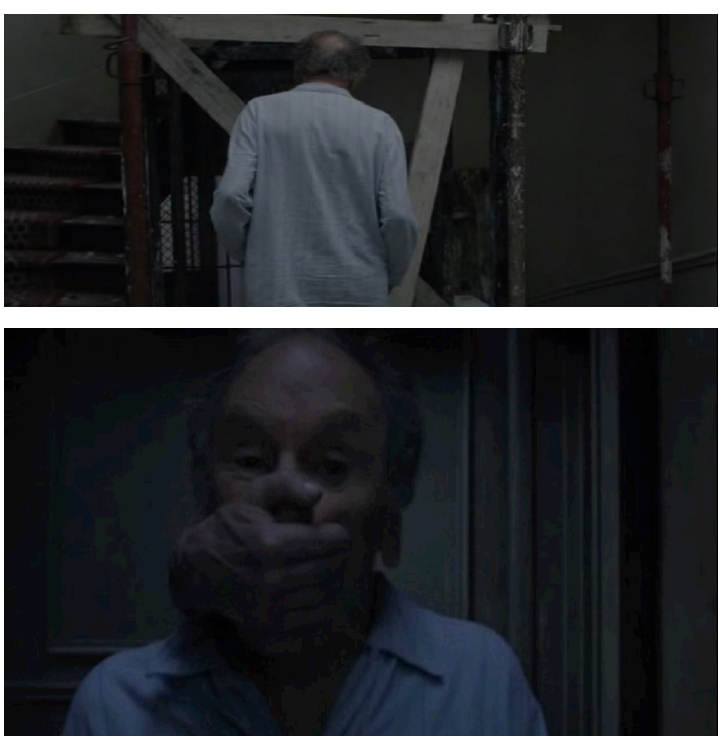

Desde el punto de vista en el que nos encontramos, la pesadilla parece representar el vivencial psíquico de Georges, presionado por el sufrimiento y el sentimiento de que no hay salida (el ascensor cerrado y astillado), demostrando que el infierno no parecen ser los otros, al estilo sartreano de Huis Clos (1943), sino que éste parece situarse en el interior de uno mismo, junto a sus más íntimos demonios. Hay pues una angustia latente en Georges, mantenida bajo la fachada de compostura que él mismo adopta ante la condición de Anne. Muchas de las preguntas de la pesadilla parecen representar las dudas existenciales que Georges se cuestiona a sí mismo: ¿por qué ocurre esto? ¿quién soy a fin de cuentas? ¿qué debo hacer? o ¿cómo debería actuar? El inconsciente ataca sigilosamente la psique del anciano protagonista. Georges demuestra una entereza y una extraordinaria fuerza que, como 
revela el fatídico sueño, eclipsan esas manos que le atrapan y no le dejan casi respirar, todo bajo la sombra de unos pies inundados en las oscuras y angustiosas aguas del pasillo.

La siguiente escena, antes del segundo punto de inflexión trágico del film, está representada por el júbilo, y el dolor, ante el transcurso de una vida que la propia Anne proclama al revisar los álbumes fotográficos y la estupefacta mirada de Georges ante las insólitas palabras y recuerdos de Anne.
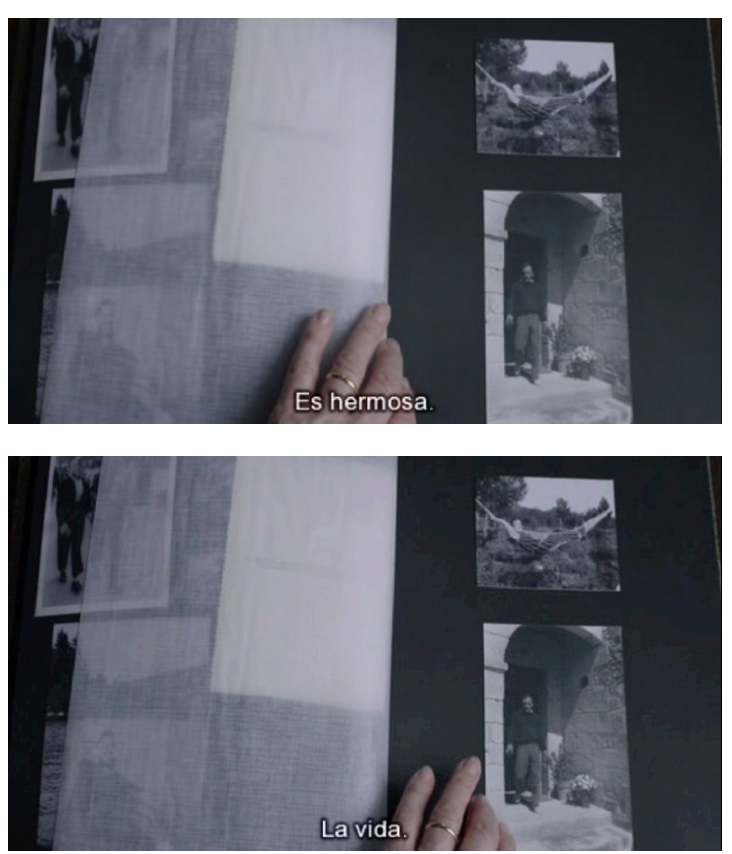

«-Anne: C'est beau...

-Georges: Quoi?-

-Anne: La vie...»

El alegato vital de Anne surge ante el fenómeno del tiempo, la fugaz historia de una vida que causa un profundo daño ante su actual revisión y que nos desvela los rasgos trascendentales de esa finitud. Es hermosa la vida que han compartido, la vida en la que ambos se han visto crecer, vida en la que han creado más vida, en la que, a fin de cuentas y en el momento presente, se van a contemplar el uno al otro descomponiéndose. La vejez, como la mirada que ésta posee del fenómeno de la muerte, son elementos tan dramáticos como cotidianos, y aquí reside parte del embrujo cinematográfico de Haneke. El director, en una de sus facetas donde acaban aunándose dos de sus grandes pasiones, el cine y el teatro, nos sacude con una violencia psicológica de gran magnitud, pero cargada al mismo ritmo de una asombrosa levedad entre escenas. El fenómeno de la vida, sea visto desde la inocencia juvenil o desde la anciana lucidez, se degrada como una sonata y tan sólo puede llegar a eternizarse ante el transcurso de toda una vida o desde la proximidad de una «buena muerte», acogiendo la sentencia rilkeana.

El segundo ataque de Anne resulta todavía más agresivo. Georges descubre cómo, durante el trascurso de la noche, Anne ha mojado la cama. Al tomar conciencia de su actual estado, el inerte rostro de la anciana protagonista muestra, paradójicamente, una impertérrita angustia. Anne queda definitivamente postrada, perdiendo casi toda capacidad lingüística y motora, pasando del «ser» al mero «estar», a ese estado vegetativo donde el individuo pasa a formar parte del mundo de los objetos materiales ${ }^{6}$. Todo lo humano que continúa prevaleciendo en Anne, y que Haneke intenta posteriormente mostrar ante esa tierna impersonalidad del amor que parece querer construirse a pesar de los límites del carácter, se desvanece ante la prevalencia de la decrepitud.

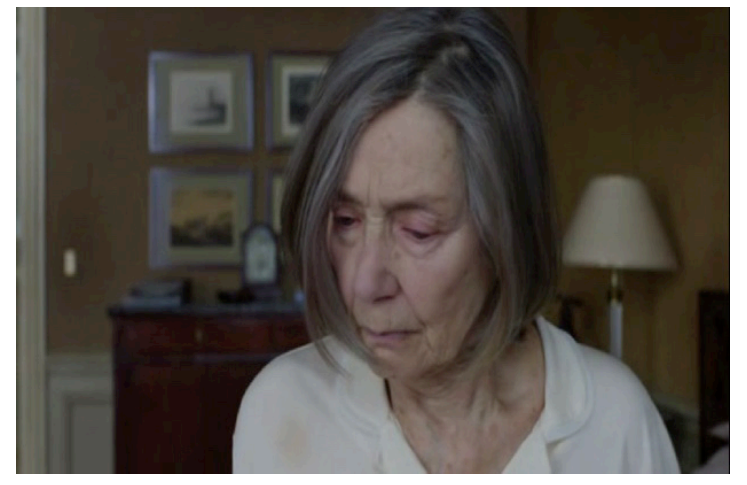

6 Hay, a partir de este momento, una profunda crítica de Haneke tanto a la ignorancia de lo humano ante un estado vegetativo (banalidad de la conversación de Eve con Anne) o, incluso, el fruto de la humillación (la enfermera que se ocupa de peinarla como si de una muñeca de trapo se tratase, obligándose a reflejar su decrepitud en el espejo). La vista crítica de Haneke no pierde el compás ante esta clase de maltratos tan presentes en el actual cuidado sanitario o en la insensibilidad de la biomedicina y la técnica. 


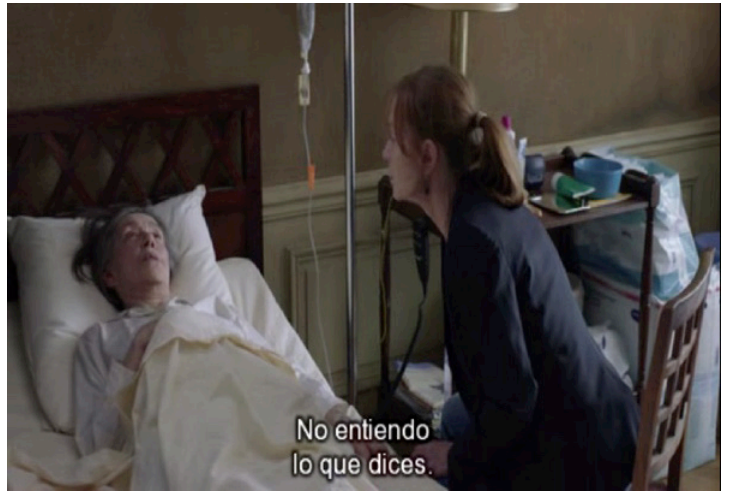

Eva vuelve a entrar en escena y de nuevo, junto a Geoff, vuelven a protagonizar uno de los puntos más críticos dentro del film hanekiano, a saber, el enfrentamiento social y personal de la enfermedad, el internamiento y mecanización del paciente y el control biomédico de la muerte7. Eva culpa a su padre y exhorta: «Je ne peux pas croire que, de nos jours, il n'a aucune possibilité de traiter ça d'une manière plus efficace ${ }^{8} »$. Ese "plus efficace " que Eva defiende es la imagen de la institucionalización y la ciega confianza en el poder de la medicina. Mientras unos discuten, Eva y Geoff, de lo que parece ser la función «operativa» frente a la enfermedad y al deterioro, Georges mantiene firmemente la voluntad de todo lo que en su momento prometió firmemente a su esposa. La problemática crítica de corte ético-moral se muestra ejemplarmente en esta escena, donde resulta sintomático el factor del aumento de esperanza de vida unido con el deterioro de la calidad y la dignidad del individuo. Esta conversación contrasta con dos de las escenas donde la profundidad y esa infinitud en la presencia del amor adquieren su carga más

7 "La decadencia, el sufrimiento físico y aún la muerte han dejado de ser pensados como hechos inherentes a la condición humana, para pasar a ser vistos en términos de ineficacia del sistema médico, o con mayor frecuencia aún, de alguna falta o descuido cometido por el propio enfermo o por sus cuidadores" (Cf. CAPONI, Sandra (2013): "La finitud y los límites del sufrimiento humano: una lectura de Amour de Michael Haneke", Revista Chilena de Salud Pública, vol. 17 (3), p. 302).

8 "No puedo creer que, en nuestros días, no haya alguna posibilidad de tratar todo esto de una forma más eficaz" (La traducción es nuestra). trágica y conmovedora. Uno de esos primeros impases es esa efímera revisión del pasado, en la cual se ofrece una de las más líricas escenas donde encontramos a Anne tocando el piano, el bello Impromptus de Schubert, junto a la mirada atenta de un Georges que añora la vitalidad y la belleza que una vez habitaron entre las paredes de su hogar. El segundo impase representa la constante preocupación de Georges al intentar ayudar a Anne a pronunciar determinadas palabras, ora a través de canciones u ora narrándole alguna historia del pasado. Tan sólo en tres segundos se desarrolla el núcleo de la escena, pero contiene ésta un juego de gestos donde, de nuevo, la belleza del momento resulta casi imperceptible. Justo después de la breve conversación que la pareja mantiene ambos quedan en silencio, Anne posa lentamente su mano sobre la de Georges, quedando sumidos en la íntima trascendencia de la mirada y una leve caricia. El espíritu de Haneke al rodar esta cinta recorre intensamente los cinco segundos de esta emotiva e impresionante poética del silencio, pues la intimidad humana no sólo está repleta de idílicas circunstancias, las raíces de lo trágico anidan también en nuestro cotidiano. Esa familiaridad, dentro de lo más temible y extraño, como posteriormente comprobaremos, es cruel, impasible, traicionera y degradante, como en las constantes negativas de Anne al recibir la comida por parte de Georges; prefiriendo así morir de hambre y dejar de ser una carga material, para ser simple testimonio de su pura voluntad de morir. $\mathrm{O}$ ante los constantes gritos de la protagonista («Mal.... mal...mal!») donde el propio Haneke parece querer mostrarnos lo que realmente le causa ese perpetuo dolor, a saber, la pesadumbre de continuar existiendo.

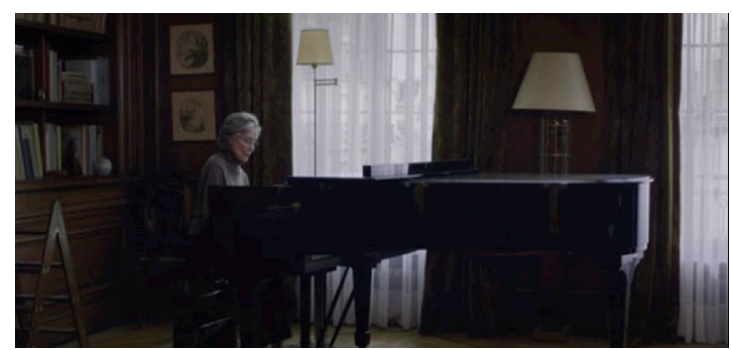




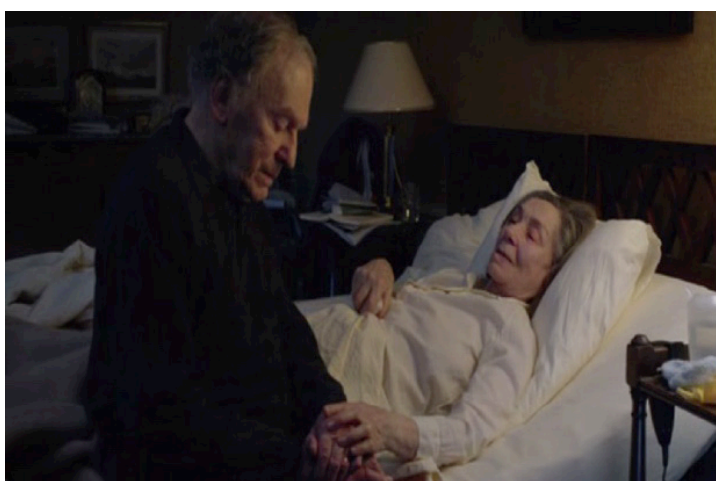

El fin del largometraje viene anunciado con la muerte de Anne. Después de calmarla con una historia de juventud ante el acoso de ese incesante dolor, Georges, en un acto infinito de amor, la ahoga con un cojín en un intento de darle la deseada y merecida paz que ha conquistado en vida. Este acto, en la perspectiva hanekiana, no debe leerse desde el prisma de la convención social (la controvertida cuestión acerca de la eutanasia) ${ }^{9}$, sino como hemos comentado, como el proceso de una última voluntad y el constante devenir del amor, desde lo puramente vital hasta el fondo de lo trágico. A la muerte de la protagonista se le añade la muerte, no visible en ninguna escena del film, pero claramente intuida, de su otro protagonista. El motor de la muerte de ambos personajes parece residir en esa plural forma del amor que hemos intentado comprobar a lo largo del análisis fílmico.

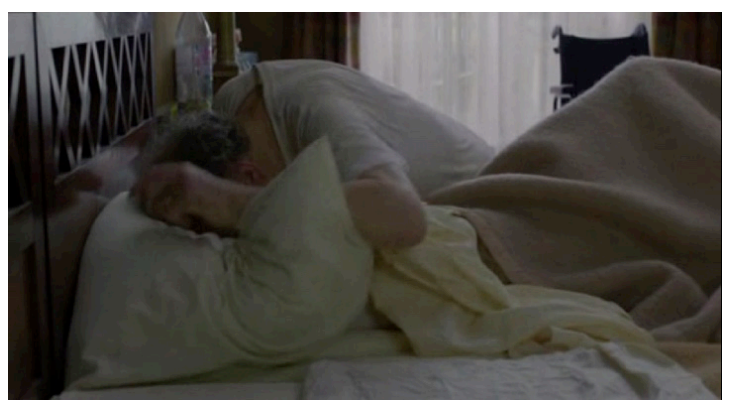

9 "Las películas, como cualquier otro arte, contienen ideas. Dichas ideas pueden ser verdaderas o falsas, morales o inmorales. Tendríamos que hacernos directamente la pregunta de qué piensa uno de las mismas. Esto no implica que disentir de las ideas signifique discrepar del valor de la obra que las personifica o de la grandeza de su creadores. Ya que quizá eso no fue lo que quiso decir, o más bien expresar, el creador [...] Las películas también contienen imágenes, sonidos y música que están relacionadas con las ideas metafóricamente o analógicamente [....]" (Cf. JARVIE, Ian (2011): Filosofía del cine: epistemología, ontología y estética, traducción de Carmen Ors, editorial Síntesis, Madrid, pp. 304-305).
El amor parece situarse más allá de toda ley, al igual que se encuentra en determinadas acciones y situaciones por encima del bien y del mal. Hay así una escena bicéfala que quizá requiera cierto grado de atención y análisis. Tanto al inicio de la degradación de Anne, como momentos antes del apogeo de su condición, una paloma entra en el piso, dedicándose a revolotear allá por donde pasa. En la primera ocasión, Georges consigue hacerla salir a través de la ventana. La segunda vez que el ave entra en el apartamento, le resulta más costoso sacarla fuera. Poco después de la muerte de Anne, Georges se dedica a prepararle el obituario en su propio lecho, recubriendo su cuerpo de flores, como se comprueba en el prólogo al film cuando los bomberos encuentran el cuerpo sin vida de Anne. Georges redacta igualmente una carta para su hija Eva, quien posteriormente protagonizará la última y desoladora de las imágenes del film; pero en el transcurso de la escritura, la paloma vuelve a aparecer y esta vez resulta todavía más costoso echarla fuera. A través de la escena contemplamos a un tranquilo Georges que acaricia a la paloma que mantiene bajo sus brazos. Este simbólico animal, en contradicción con su usual interpretación, parece mostrar el reflejo de la propia muerte. Las primeras veces que entra en el apartamento, e incluso representada pictóricamente en numerosas ocasiones en una de las partes del salón, el protagonista intenta, no sin numerosos rodeos, sacarla inmediatamente de ese espacio. Pero, una vez fallecida la protagonista, el anciano la atrapa definitivamente, se sienta tranquilo y acaricia al animal en posesión de cierta armonía; expresando de nuevo en esta metáfora animal una "inquietante extrañeza" dentro de la narración fílmica.

La paloma parece representar aquel nómada, su cara más siniestra, del cual jamás nos preguntamos a dónde se dirige, de dónde viene o con quién va, son tan numerosas y están en sitios tan dispares que perdemos completamente la noción de su posible singularidad. El cine de Haneke juega con toda esta carga metafórica, y con numerosos símbolos que pierden en ocasiones 
su ancestral significado, y es en gran medida este factor el que apunte a su faceta de director-artista, dejando al espectador la tarea del desvelamiento simbólico. Momentos después, tumbado en la cama, Georges escucha un ruido proveniente de la cocina. Al acercarse tan sólo puede asombrarse ante el hecho de observar como Anne se dedica a fregar los platos, comunicándole al mismo tiempo que van a salir. De nuevo el agua cae y cierra un ciclo de sensaciones contradictorias a lo largo del largometraje.
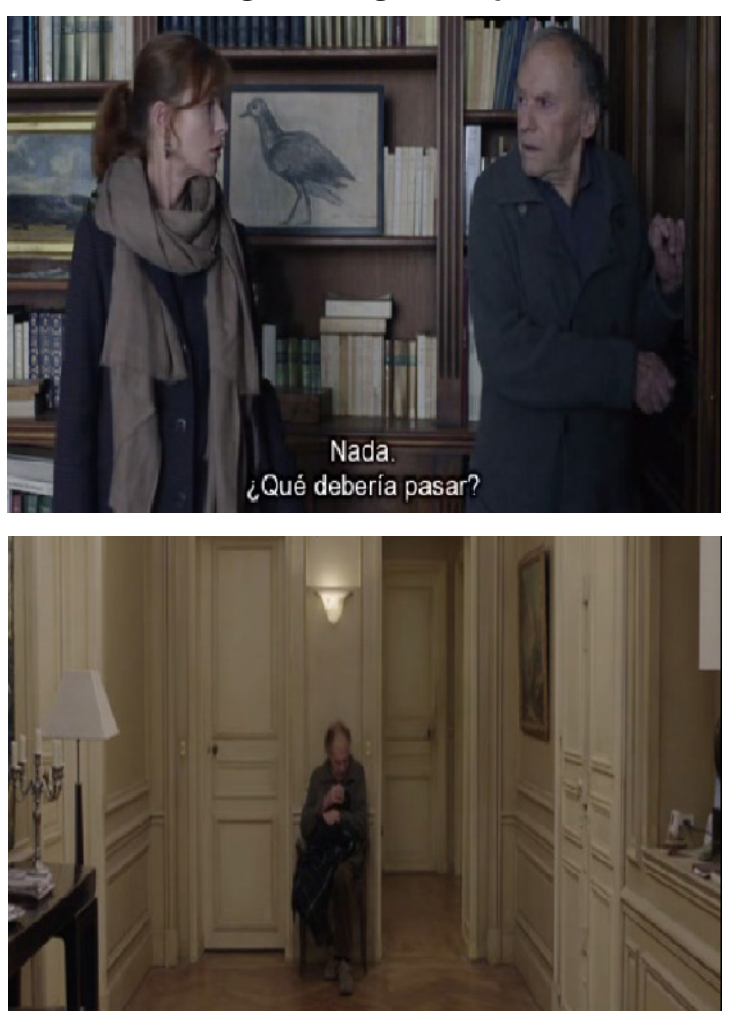

El austero final que Haneke nos prepara tiene trazos románticos, el reencuentro de ambos amantes justo después de la muerte, pero quizás el propósito va mucho más allá de ese romántico fotograma. Al igual que la paloma, atrapada bajo las cuatro paredes del apartamento, Anne y Georges salen de nuevo de la morada donde su amor se ha visto conjugado, hasta tal punto que quizá la única solución sea la rememoración de aquel sencillo amor que encierra tan grandes complejidades y que encuentra de este modo un lugar donde acabar de eternizarse.
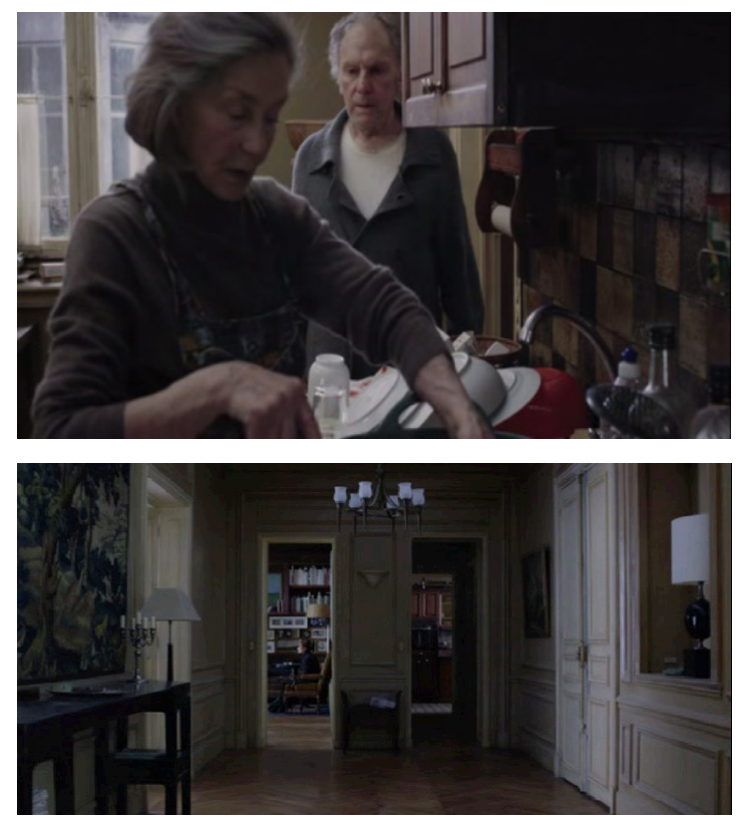

\section{3. (UN)HEIMLICH: HACIA UNA POÉTICA DEL EXTRAÑAMIENTO}

Como comentábamos en el anterior análisis del film hanekiano, la inesperada, pero íntegra parte de la fugacidad existencial, de la enfermedad y la degradación proporcionan, tanto en Anne como en Georges, cierto sentimiento de extrañamiento con el otro y consigo mismo. Esta extrañeza provoca cambios repentinos en la esfera psíquica de ambos personajes y merece atención ante la posible relación que podrían mantener con la formula freudiana de Heimlich/Unheimlich (lo familiar/ lo extraño o, como reza la traducción hispana, "lo siniestro"). Intentaremos comprender el significado de ambos términos dentro del aparato conceptual psicoanalítico para, a posteriori, intentar elaborar, a partir de ellos, una mejor comprensión de este fenómeno del extrañamiento, tan cercano a lo más cotidiano, que podemos comprobar en Amour.

La toma de contacto freudiana con este extraño binomio es, como él mismo lo afirma, "más de carácter estético que psicoanalítico [...] sin embargo, puede darse la ocasión de que sea impelido a prestar interés a determinado sector de la estética"10. Lo Unheimlich, traducido al castellano co-

10 Cf. FREUD, Sigmund (1972-1975): Obras completas (volumen 7, 
mo "lo siniestro", es el objetivo psicoanalítico al que Freud apunta, "dicho concepto está próximo a los de lo espantable, angustiable, espeluznante [...]"1". Lo siniestro, la Unheimlich, sería todo aquello "espantoso" o "angustiable" que afecta a las cosas conocidas y familiares desde tiempo atrás. Ofrece Freud así una curiosa etimología del término, uniéndolo a su correlativo, "Heimlich" (intimo, secreto, hogareño o familiar), precisando que es exactamente esa amplia y profunda familiaridad la que nos proporciona el fenómeno de la angustia o del espanto. Unheimlich, en Schelling por ejemplo, como Freud indica, "sería todo lo que debía haber quedado oculto, secreto, pero que se ha manifestado"12. De este modo, Heimlich cuyas voces acaban en cierta ambivalencia de significados termina coincidiendo con su antítesis (Un-heimlich). Así, Unheimlich es una especie de Heimlich. Freud se dedica a partir del origen terminológico de los términos a intentar plasmar dichos conceptos con algunos ejemplos literarios (Hoffmann o Poe). Por lo tanto, lo siniestro no sería realmente nada novedoso, sino más bien algo que siempre ha sido familiar a la vida psíquica y que se torna extraño en el proceso de represión o angustia ante un fenómeno cualquiera. Hay así, como Freud indica en uno de los ejemplos expuestos, una íntima relación del fenómeno del Unheimlich con nuestras posibles relaciones con la muerte. Existen pues:

"dos factores que explican esta detención del desarrollo: la fuerza de nuestras relaciones afectivas primarias y la incertidumbre de nuestro conocimiento científico. La biología aún no ha logrado determinar si la muerte es el destino ineludible de todo ser viviente o si sólo es un azar constante, pero quizá evitable, en la vida misma [...] el primitivo temor ante los muertos y la muerte conserva su poder"13.

1916-1924), traducción directa del alemán por Luis López-Ballesteros y de Torres; ordenación y revisión de los textos realizada por Jacobo Numhauser Tognola, Biblioteca Nueva: Madrid, p. 2483.

11 Idem.

12 Idem, p. 2487.

13 Idem, p. 2498.
Esta argumentación freudiana puede entrar, como comprobaremos, directamente en relación con el film de Haneke. Es justamente este fenómeno de la muerte el que se presenta como un extraño -y al mismo tiempo como el proceso de una clara aceptación desde el principio en Anne- dentro de la propia cotidianidad ante toda relación afectiva (la relación de Anne y Georges) o la incertidumbre de ese conocimiento científico-médico (relación entre Eva y Georges). En determinados momentos, el aparato psicoanalítico parece agotarse ante la técnica fílmica, intentando encontrar una vía de fuga, como ya el propio Freud ha comentado en el texto, a través del fenómeno estético; llegando hasta el punto de relacionar la experiencia de "lo siniestro" [(Un)heimlich] con la ficción. Para Freud, esto alcanza un nivel (meta)literario, pero desde nuestra perspectiva intentaremos aplicar cierto grado de argumentación a la perspectiva puramente meta-cinematográfica:

"Lo siniestro en la ficción [...] merece un examen separado. Ante todo, sus manifestaciones son mucho más multiformes que las de lo siniestro vivencial, pues lo abarca totalmente, amén de otros elementos que no se dan en las condiciones del vivenciar. El contraste entre lo reprimido y lo superado no puede aplicarse, sin profundas modificaciones, a lo siniestro de la obra poética, pues el dominio de la fantasía presupone que su contenido sea dispensado de la prueba de realidad [...] la ficción dispone de muchos medios para provocar efectos siniestros que no existen en la vida real"14.

La ficción, en nuestro caso particular la correspondiente a la cinematografía, alberga la capacidad de crear nuevas posibilidades dentro del fenómeno de lo siniestro. Al tratarse de casos literarios muy concretos, Freud acaba opinando que dichos casos "no existirán en la realidad". La experiencia cinematográfica, y sobre todo, la trayectoria existencial que ocupa la poética de Amour, a pesar de ser un artilugio más de la industria cinematográfica, y del microcosmos intelectual de un singular realizador, adquiere cierta

14 Idem, p. 2503. 
potencialidad humana al saber que aquello que resulta extraño -o siniestro- en el film, el fenómeno de la degradación y la muerte, es también transmutable a otro fenómeno, a saber, el fenómeno del amor. Quizá, más que la extrañeza ante un cuerpo que deviene cada vez más enfermo, decrépito e inútil, la poética de Haneke en Amour ronde más en este punto una poética del extrañamiento que concierne directamente a la experiencia, impersonal como ya hemos comentado, del amor. Este sentimiento, tan familiar para cada uno de nosotros, adquiere el cariz de lo más sombrío, "siniestro" o extraño que acaba reflejando a todos los espectadores el espejo en el que ambos personajes se miran constantemente dentro de la pantalla. Al mismo tiempo, lo más extraño, lo que quizá nuestra vida rechaza más profundamente, el fenómeno de la muerte ${ }^{15}$, queda así asumido como un aspecto más de lo cotidiano, se impregna dicho fenómeno dentro del film a las paredes del hogar. Un espacio de comunión, este hogar, donde la pareja ha compartido gestos, emociones, caricias, carnalidad, pero también sufrimiento, descomposición y, sobre todo, cierta desesperación consciente e inconsciente (recordemos la pesadilla de Georges). El fenómeno de lo Unheimlich parece revelarse, junto con lo Heimlich, aunque diste en cierta manera de la clásica concepción psicoanalítica, en el último film de Haneke. Desconocemos si el director tuvo contacto en sus lecturas con el texto freudiano, pero a través del film ha conseguido una inesperada y personal muestra de esta "poética del extrañamiento" que, a la postre, acaba siendo el reflejo en el espejo de una clara poética de lo cotidiano. Y así, el Amor, ese impersonal, acaba siendo el doppelgänger de ambas poéticas que se encuentran, que se distancian y batallan pero, en última instancia, acaban siendo sometidas al influjo de la paradoja humana. Como comenta Julia Kristeva:

15 «En outre, si la douleur isole Anne et abîme la complicité au sein du couple, la perspective de la mort achève d'introduire une étrange distance entre eux» (Cf. DELMOTTE, Benjamin (2012): «Comment finir? Amour de Michael Haneke», Esprit, 12, Décembre, p. 126). "le choc de l'autre, l'identification du moi avec ce bon ou mauvais autre qui viole les limites fragiles du moi incertain, seraient donc à la source d'une inquiétante étrangeté dont l'aspect excessif, représenté en littérature, ne saurait cacher la permanence dans la dynamique psychique «normale»»16.

Ese choque del ego con otro yo, frágil, enfermo, decadente, cercano a una siniestra -pero también familiar- experiencia, ejerce en mi persona una fuerza impersonal lejana que acaba asemejándose a la experiencia del otro (el caso de Georges sería quizás el más indicado ante este aspecto). El extraño, el reflejo en el trágico espejo, en el cual Georges se refleja día tras día y Anne acaba negándose a que este mismo espejo le devuelva una imagen degradada, el límite de lo corpóreo, se encuentra en nosotros luchando en cierta manera contra los ataques de nuestro inconsciente. El «yo», o el «nosotros», tan sólido y eterno como tendemos a conceptualizar, ante el reconocimiento de este sentimiento de «inquietante extrañeza», nos ofrece una muestra de la fragmentación de ese siniestro ser que se manifiesta como extranjero para nosotros mismos. De este modo, una visión natural de esa inquietante imagen cinematográfica, como opina Stanley Cavell, «consiste en su capacidad para percibir cada movimiento, cada posición y, en especial, cada postura y cada gesto humano, por fugitivo que sea, como cargados de su poesía, o bien, podríamos decir, de su lucidez $»^{17}$. Lo más siniestro de nuestra condición viene cargado de esta potencial lucidez que, en este caso, ayuda a desvelarse a través de la carga fílmica.

\section{A MODO DE CONCLUSIÓN}

Ante todo lo analizado y comentado, no cabe poner en duda que la cinematografía de Michael Haneke parece siempre resultar un intento por parte del director de ocupar sus manos en la infinitud

16 Cf. KRISTEVA, Julia (1988): Étrangers à nous-mêmes, Paris, Fayard, p. 278.

17 Cf. CAVELL, Stanley (2008): El cine, ¿puede hacernos mejores?, Katz editorial, Buenos Aires, p. 40. 
del piano, en los compases de la Bagatela que acompaña al film, dando cuerda y melodía a su imaginación; al igual que con la tarea propia del lenguaje, dentro de los sombríos y entrecruzados laberintos de la creación poética. La filmografía del director austriaco consigue aunar los frutos de las artes, violentando la imagen, el lenguaje y la conciencia de cada uno de los espectadores. Haneke es, a pesar de todas las etiquetas otorgadas, un misterioso clarividente entre abismos y un fiel adepto del arte de "penser contre soi », acertada expresión con la que Cioran calificó a literatos como Dostoievski, Baudelaire, Shakespeare o Stendhal. El cine de Haneke, y en especial este último largometraje, juega con los claroscuros de la condición humana, nos arroja a nuestra propia extrañeza, y es en ésta donde encontramos a nuestro más íntimo compañero de viaje. Sólo a través de estas rupturas narrativas, sobre todo en el caso de la cinematografía, en las cuales el binomio Heimlich/Unheimlich aflora con toda su potencia, se termina preguntando por todo aquello que el inconsciente recela. El cine cuenta así con un atributo esencial, es una de las formas artísticas más jóvenes y pioneras de los últimos siglos, y como comenta el propio Haneke en su discurso al recibir el reciente Premio Príncipe de Asturias 2013 a las Artes:

«[...] a pesar de esta juventud [el cine] se ha hecho culpable como casi ninguna otra forma de expresión artística. Ni la literatura, ni el teatro han conseguido alejarse tanto de su propia vocación [...] el cine, con su peligrosa eficiencia en temas propagandísticos, ha puesto en peligro el destino de miles de personas. Me parece demasiado fácil negarles sin más a estas películas su carácter artístico, señalándolas como meros desvaríos. No se puede negar a cineastas como Riefenstahl o Eisenstein su alta capacidad estética [...] El cine, en cambio, es un medio de avasallamiento. Ha heredado las estrategias efectistas de todas las formas artísticas que existían antes que él y las usa eficazmente. Todos conocemos el efecto de los cuadros de tamaño sobrenatural y los tonos sobre nuestra pulsación y nuestro bienestar general. En eso radica la fuerza del cine y su peligro. Ninguna forma artística es capaz de convertir tan fácil y directamente al re- ceptor en la víctima manipulada de su creador como el cine. Este poder requiere responsabilidad. ¿Quién asume esta responsabilidad? ¿Surge la fundada desconfianza de aceptar el cine como forma artística de esta responsabilidad tan frecuentemente no asumida? ¿La manipulación no es lo contrario de la comunicación? ¿Y no es la comunicabilidad y el respeto ante el tú del receptor una condición básica para poder hablar de arte en general? [...]»18

El final de todo lo efímero, desde una determinada posición dentro de la estética cinematográfica, hasta una posición psicoanalítica que coincide con cierta crítica de la cultura, parece resultar el motor que activa la auto-conciencia de la finitud, pero igualmente extraño salvoconducto ante el amor, el deseo, el pensamiento o todo resquicio sentimental. En definitiva, viviendo y experimentando esa «invisibilidad de la belleza» que, como en ocasiones, oprime y desespera, en otros momentos y circunstancias desvela cada pequeño y tierno acto que inmortaliza en un instante lo que el tiempo finito no llega a captar. Amour es así extrañeza, degradación, pesadumbre, enfermedad, consternación, angustia, pero también, amor, cuerpo, tacto, alegría, optimismo...un póstumo retrato de la vida a fin de cuentas. Es pues de este modo, o de estos tan plurales modos, como la filmografía de Michael Haneke, y muy especialmente su último film, Amour, parecen seguir cumpliendo potencialmente con este preciado cometido.

18 El discurso íntegro de Michael Haneke se encuentra disponible en: http://www.fpa.es/es/premios-principe-de-asturias/premiados/2013-michael-haneke.html?texto=discurso\&especifica=0. La cursiva es nuestra. 


\section{BIBLIOGRAFÍA}

DELMOTTE, Benjamin: «Comment finir? Amour de Michael Haneke», Esprit, Décembre, 2012/12.

WHEATLEY, Catherine (2009): Michael Haneke's Cinema. The Ethic of the Image, Berghahn Books, USA.

TRÍAS, Eugenio (2013): De cine. Aventuras y extravíos, Galaxia Gutenberg, Barcelona.

JARVIE, Ian (2011): Filosofía del cine: epistemología, ontología y estética, traducción de Carmen Ors, editorial Síntesis, Madrid.

DOKIC, Jérôme: « L'inquiétant étrangeté et autres sentiments existentiels négatifs », disponible online en la red (http://j.dokic.free.fr/philo/pdfs/Unheimlichkeit.pdf).

KRISTEVA, Julia (1988): Étrangers à nous-mêmes, Paris, Fayard.

HANEKE, Michael (2013): Amour, Cameo Media, D.L., Barcelona.

"Discurso Premio Príncipe de Asturias a las Artes», Octubre, 2013, disponible online en la red.

PARENT, Pierre-Paul (1993): «L'inquiétante étrangeté, la Chose et l'écriture de la subjectivité», Filigrane, num. 2, pp. 161-171.

CAPONI, Sandra (2013): "La finitud y los límites del sufrimiento humano: una lectura de Amour de Michael Haneke", Revista Chilena de Salud Pública, vol. 17 (3).

FREUD, Sigmund (1972-1975): Obras completas (volumen 7, 1916-1924), traducción directa del alemán por Luis López-Ballesteros y de Torres; ordenación y revisión de los textos realizada por Jacobo Numhauser Tognola, Biblioteca Nueva, Madrid.

CAVELL, Stanley (2008): El cine, ¿puede hacernos mejores?, Katz editorial, Buenos Aires. 